\title{
Primary Burkitt's Lymphoma of the Ovary in Early Weeks of Pregnancy - A Case Report
}

\section{Primäres Burkitt-Lymphom des Ovars in der Frühschwangerschaft - Fallbericht}

Authors

Affiliation
H. Steininger, J. Gruden, H. Müller

Pathologisches Institut, Friedrichshafen

Key words
adolescence
ovarian tumour
pregnancy
Schlüsselwörter
Adoleszenz
Ovarmalignom
- Schwangerschaft

received 17.7.2012

revised 21.8.2012

accepted $\quad 31.8 .2012$

\section{Bibliography}

DOI http://dx.doi.org/ 10.1055/s-0032-1327777

Geburtsh Frauenheilk 2012; 72: 949-952 @ Georg Thieme

Verlag KG Stuttgart · New York ISSN 0016-5751

\section{Correspondence}

Prof. Helmuth Steininger

Pathologisches Institut

Röntgenstraße 2

88048 Friedrichshafen

helmuth_steiningerpath@

hotmail.com

\section{Abstract \\ $\nabla$}

Primary ovarian Burkitt's lymphoma is a rare tumour predominantly affecting children and young adults. We report here on a 17-year-old pregnant woman with a Burkitt's lymphoma of the left ovary. After tumour removal and induced abortion, the patient underwent polychemotherapy. Full remission was achieved 7 months after the initial diagnosis.

\section{Introduction}

\section{$\nabla$}

Malignant lymphomas of the female genital tract are unusual, and less than $1 \%$ of patients with a diagnosis of malignant lymphoma present with an enlarged ovary as the initial manifestation [1, 2]. In more than $90 \%$ of cases, the malignancy is a B-cell non-Hodgkin lymphoma, often with secondary involvement due to systemic disease [2, 3].

As lymphatic tissue is normally not present in the ovary, primary malignant lymphomas of the ovary are rare. They constitute less than $1 \%$ of all malignant lymphomas and the literature on primary malignant ovarian lymphomas consists only of case reports or small series [4-10].

Some authors have proposed criteria which could be used to differentiate between secondary and primary malignant lymphomas $[1-3,10]$, and these criteria will be discussed below.

\section{Case Report and Morphological Findings $\nabla$}

A 17-primagravida was admitted to hospital in the 11th week of pregnancy $(10+5)$ for strong, acute onset, primarily left-sided, abdominal pain. Vaginal sonography showed an enlarged uterus containing a vital single foetus with a crown-

\section{Zusammenfassung \\ $\nabla$}

Das primäre ovarielle Burkitt-Lymphom ist ein seltener Tumor, der bei Kindern und jungen Erwachsenen auftreten kann. Im vorliegenden Fall handelt es sich um eine 17-jährige, schwangere Patientin mit Befall des linken Ovars. Nach Entfernung des Tumors und Abortinduktion wurde eine Polychemotherapie durchgeführt, unter der es 7 Monate nach Diagnosestellung zur Vollremission kam.

rump length of $4 \mathrm{~cm}$. A $7.5 \mathrm{~cm}$ large solid pelvic mass was visible at the left adnexa.

Laparoscopic investigation showed a tumour of the left ovary of unclear malignancy and origin. The patient underwent laparatomy with removal of the left ovary. There were no other pathological intra-abdominal findings. The peritoneum was smooth; the right adnexa, omentum and liver were unremarkable; no enlarged lymph nodes were noted.

Macroscopically, the resected specimen consisted of a pear-shaped tumour weighing $114 \mathrm{~g}$ and measuring $7.5 \times 6.5 \times 4 \mathrm{~cm}$ ( $\bullet$ Fig. 1 ). The cut surface of the tumour had a homogeneously light grey to light brown colour, with small cysts and a central blood supply. It was not possible to differentiate the tumour from normal ovarian tissue either macroscopically or histologically.

Microscopic investigation showed a lymphoid tumour with blast tumour cells, some areas of cohesive growth, and interspersed macrophages, giving it a "starry sky" appearance ( $\bullet$ Fig. 2). Tumour cells were strongly positive for CD45, CD20, CD10 and CD38. Positivity for bcl-6 was slightly weaker, and the tumour was bcl-2 negative. The tumour proliferation fraction (Mib 1) was approx. 90\% ( Fig. 3); the tumour was EBV-LMP negative and both oestrogen receptor-negative and progesterone receptor-negative. 


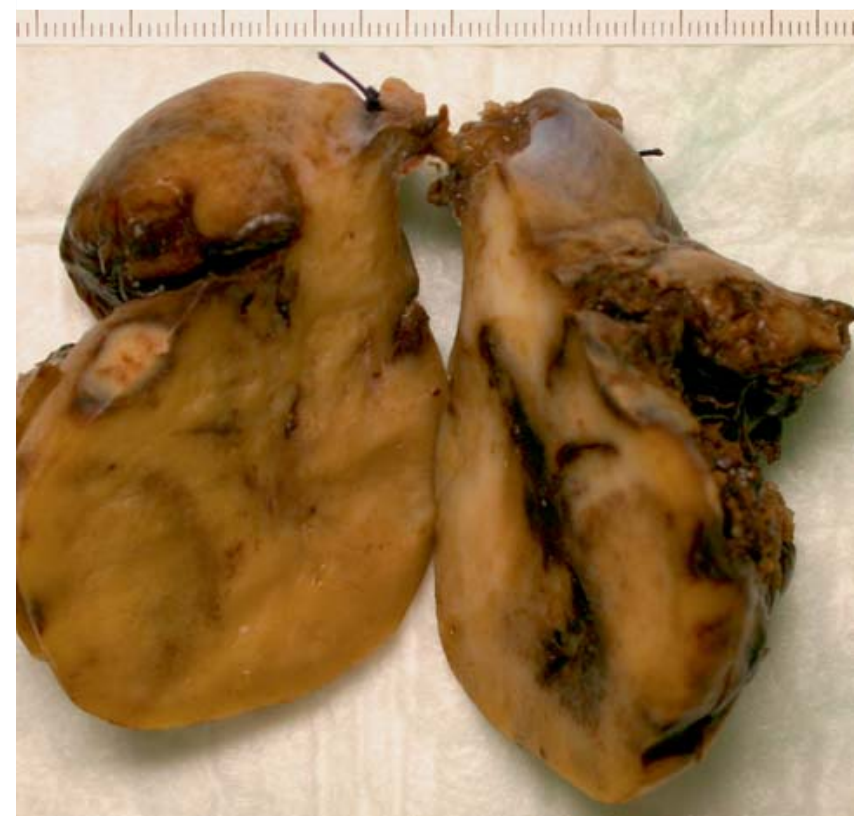

Fig. 1 Macroscopic image of the left ovary showing complete invasion of the ovary (scale in $\mathrm{cm}$ ).

Cytogenetic investigations showed a break in the area of the c-myc gene with translocation $\mathrm{t}(8: 14)$ and a clonal immunoglobulin heavy chain gene rearrangement. Histological, immunohistochemical, and cytogenetic findings were consistent with the diagnosis of Burkitt's lymphoma.

No enlarged lymph nodes were found on investigation immediately after the diagnosis of Burkitt's lymphoma.

Enzyme-linked immunosorbent assay (ELISA) for HIV was negative.

Bone marrow investigation done 10 days after removal of the tumour did not show the presence of any lymphoma. The liver, spleen and other organs were unremarkable; the lymph nodes were still not enlarged. Haemogram and differential blood count were normal. However, over the next few days the cervical lymph nodes rapidly proliferated and became enlarged (up to $17 \mathrm{~mm}$ ),
Table 1 Ann Arbor staging system (1971).

\begin{tabular}{|ll|}
\hline Stage & $\begin{array}{l}\text { Involvement } \\
\text { Cancer is located in a single lymph node region (I) or a single extra- } \\
\text { lymphatic organ ( } \mathrm{I}_{\mathrm{E}} \text { ) }\end{array}$ \\
\hline II & $\begin{array}{l}\text { Involvement of two or more lymph node regions (II) or localised } \\
\text { involvement of extra-lymphatic organ or tissue with involvement } \\
\text { of one or more lymph node regions (II }) \text { on the same side of the } \\
\text { diaphragm }\end{array}$ \\
\hline III & $\begin{array}{l}\text { Cancer is located in lymph node regions on both sides of the } \\
\text { diaphragm (III), sometimes accompanied by localised extra-lym- } \\
\text { phatic organ or tissue involvement (III }) \text { or splenic involvement } \\
\left.\text { (IIII) or both (III } I_{\mathrm{SE}}\right)\end{array}$ \\
\hline IV & $\begin{array}{l}\text { Diffuse or disseminated involvement of one or more extra-lym- } \\
\text { phatic organs or tissues, with or without enlarged lymph nodes }\end{array}$ \\
\hline
\end{tabular}

resulting in a clinical diagnosis of a stage III lymphoma according to the Ann Arbor staging system ( $\bullet$ Table 1 ). Polychemotherapy was indicated based on the recommendations of the German Multi-centre Study Group for Adult Acute Lymphoblastic Leukaemia (GMALL B-ALL/B-NHL protocol 2002).

Because of the embryotoxicity of the cytostatic drugs and the incalculable risks during the therapy-induced aplasia phases, an abortion was induced 14 days after diagnosis in the 13th week of pregnancy with subsequent curettage. The embryo was a male foetus with appropriate foetal development for age, weighing $27 \mathrm{~g}$ with a crown-rump length of $7.5 \mathrm{~cm}$ and without visible external or internal abnormalities. A few days after the abortion, the disease had progressed rapidly, with pelvic bone pain and pain in the lumbar vertebral column as well as night sweats. The patient developed diffuse bone marrow disease and a left parauterine mass in the small pelvis.

After pre-phase therapy with cyclophosphamide and prednisolone, port implantation was done and treatment block A1 of the B-NHL protocol was administered (rituximab d 7, vincristine $\mathrm{d} 8$, high-dose methotrexate $\mathrm{d} 8$, ifosfamide $\mathrm{d} 8-13$, etoposide $\mathrm{d} 11$ and 12 , and $2 \times$ triple intrathecal prophylaxis with methotrexate, cytarabine and dexamethasone on d 10 and d12). Morphine therapy and complete parenteral feeding were temporarily necessary for grade IV mucositis. The patient developed fever in the

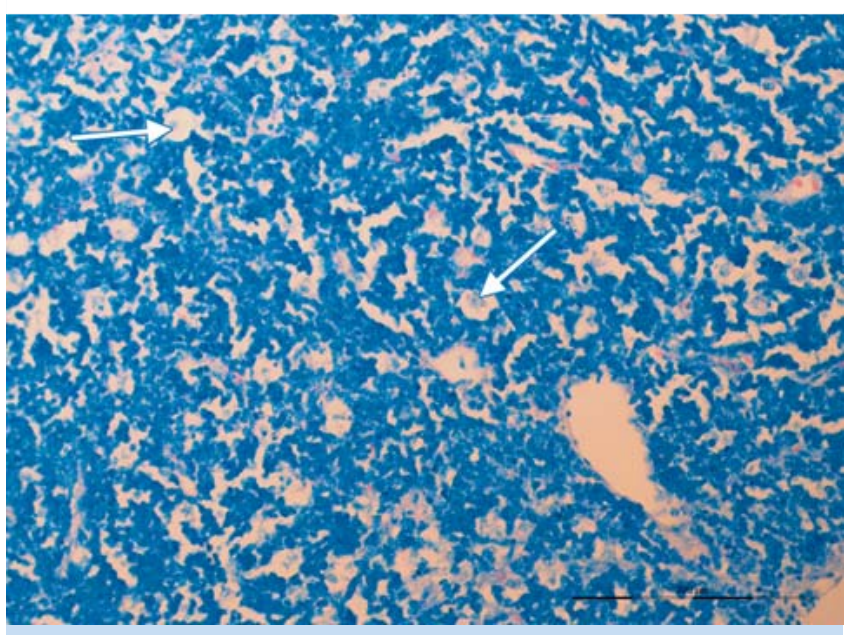

Fig. 2 Histological image showing lymphoblastic infiltrate and a starry sky pattern (white arrows). Giemsa $\times 200$.

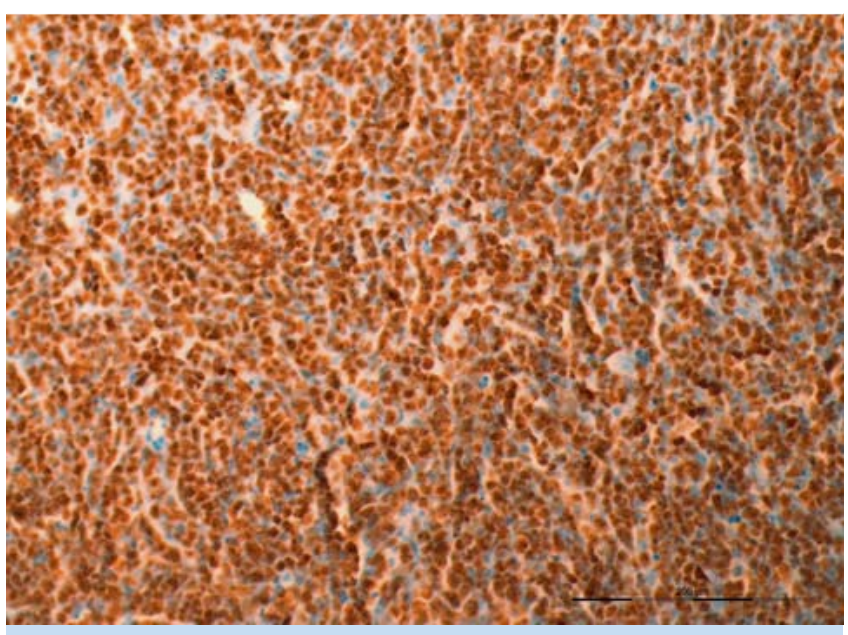

Fig. 3 High tumour proliferation fraction of approx. 90\%. Immunohistochemistry $(\mathrm{MiB} 1) \times 200$. 
subsequent aplasia phase and was given antibiotics. HSV1 virus DNA in the pharyngeal aspirate made treatment with acyclovir necessary. After aplasia had ended, improvement was rapid and medication was discontinued. Chemotherapy was then continued with the administration of block treatments B1 and C1 according to the B-NHL protocol. Complications of fever and mucositis recurred. Chemotherapy was completed 7 months after diagnosis and after the administration of block treatments A2, $\mathrm{B} 2$ and $\mathrm{C} 2$. The disease was in complete remission and the patient was in a stable general condition with a Karnofsky index of $90 \%$.

\section{Discussion}

Dis

Burkitt's lymphoma is a rapidly growing tumour with a generally unfavourable prognosis. The entity was first described in 1958 by Burkitt as a "sarcoma" occurring in African children [11]. In fact, it is a highly malignant, B-cell non-Hodgkin lymphoma consisting of monomorphic, medium-sized cells with basophilic cytoplasma; it has a high proliferation fraction, a cohesive growth pattern and displays a so-called starry-sky pattern [12]. Primary extra-nodal manifestation is common. Almost all cases showed translocation of the c-myc proto-oncogene from its normal position on chromosome 8 to a region on chromosome 14 , which codes for heavy chains [12].

Epidemiologically, Burkitt's lymphoma is differentiated into 3 main forms $[12,13]$.

1. The African or endemic form, which occurs predominantly in children, is linked to the Epstein-Barr virus, and manifests in the lower jaw or the abdominal organs. In younger women it shows a predilection for the genital tract [8].

2. The non-endemic or sporadic form which occurs in young adults and commonly involves abdominal locations.

3. The form associated with immunodeficiency (e.g. HIV infection) which generally manifests as nodal disease.

We describe here a case of non-endemic (sporadic) Burkitt's lymphoma.

Vang et al. [10] reported on 8 primary ovarian non-Hodgkin lymphomas of which 6 were B-cell lymphomas and 2 were T-cell lymphomas. The B-cell lymphomas were differentiated further into 3 diffuse large-cell lymphomas, 2 follicular lymphomas and 1 Burkitt's lymphoma. In a large series of 186 primary and secondary lymphomas of the female genital tract followed up for more than 30 years [1], the most common type of lymphoma was found to be diffuse large-cell B-cell lymphoma, with Burkitt's lymphoma in second place. The third most common type was follicular lymphoma, followed by the other types. In the female genital tract, the organs most commonly involved were the adnexa, followed by the uterine body, uterine cervix, the ectocervix, the vagina and vulva. Of the 23 Burkitt's lymphomas of the adnexa, 9 were classed as primary and 14 as secondary tumours. Particularly unusual in this collective was the high rate of primary lymphomas, which was given as $63 \%$. The findings of the authors are contrary to those of other authors who report that primary lymphomas are extremely rare entities $[2,3,8]$.

The following criteria - similar to those of Fox [3] - have been proposed by Kosari [1] for a diagnosis of a primary lymphoma:

1. At the time of initial diagnosis the tumour is limited to the female genital tract, with involvement of one or more organs (e.g. ovary and uterine body).
2. Complete examination of the patient shows no indications for disease in any other part of the body.

3. Peripheral blood picture and bone marrow contain no abnormal cells indicative of leukaemia.

4. No involvement of distant organs over a period of 6 months.

Other authors $[2,10]$ consider Ann Arbor stage $\mathrm{I}_{\mathrm{E}}(\mathrm{E}=$ involvement of extra-lymphatic organs, $\triangle$ Table 1) to be sufficient for the diagnosis of primary lymphoma, while other authors completely dispense with giving their criteria [4-7,9]. Even if the case described here did not comply with No. 4 of Kosari's criteria - as there was cervical lymph node involvement and infiltration of bone marrow already after one month - we are of the opinion that the tumour was a primary ovarian Burkitt's lymphoma. At diagnosis the tumour was stage $\mathrm{I}_{\mathrm{E}}$; the lymphoma was already relatively large and examination done immediately after the diagnosis showed no involvement of other organs. Bone marrow and peripheral blood picture were unremarkable.

Most Burkitt's lymphomas with involvement of the ovaries and appendix affect children or young adults. Typical presenting symptoms are abdominal tumours with swelling and pain and, occasionally, ileal symptoms due to rapid growth of the tumour [9].

The differential diagnosis of malignant ovarian lymphoma includes granulosa cell tumours, dysgerminoma, hypercalcaemic small cell ovarian carcinoma, poorly differentiated ovarian carcinoma and ovarian metastasis $[8,14]$.

Burkitt's lymphoma is potentially curable with aggressive chemotherapy, and particularly patients with localised Burkitt's lymphoma often have a favourable course [4]. Early diagnosis and the capacity to tolerate aggressive chemotherapy are decisive for prognosis [5,7].

The patient described here has been in complete remission since 4 years and remains free of symptoms. She was delivered of a healthy girl by caesarean section three years after the initial diagnosis.

\section{Acknowledgements}

$\nabla$

We would like to thank Prof. Dr. Möller (Referenzzentrum für Hämatopathologie und Lymphomdiagnostik, Institute for Pathology, University Clinic Ulm) for carrying out the cytogenetic investigation.

Our thanks also go to CA Dr. E.-D. Mauch (Lindau Hospital) and Dr. E. Zink (Lindenberg) for providing the clinical and anamnestic data.

\section{Conflict of Interest \\ $\nabla$}

None.

\section{References}

1 Kosari F, Daneshbod Y, Pawaresch $R$ et al. Lymphomas of the female genital tract. A study of 186 cases and review of the literature. Am J Surg Pathol 2005; 29: 1512-1520

2 Monterroso V, Jaffe ES, Merino MJ et al. Malignant lymphomas involving the ovary. A clinicopathologic analysis of 39 cases. Am J Surg Pathol 1993; 17: 154-170

3 Fox H, Langley FA, Govan ADT et al. Malignant lymphoma presenting as an ovarian tumour: a clinicopathological analysis of 34 cases. $\mathrm{Br}$ J Obstet Gynaecol 1988; 95: 386-390 
4 Baloglu H, Turken O, Tutuncu L et al. 24-year-old female with amenorrhea: bilateral primary ovarian Burkitt lymphoma. Gynecol Oncol 2003; 91: 449-451

5 Creatsas GK, Hassan EA, Deligeoroglou EK et al. Non-Hodgkin's ovarian lymphoma during adolescence: report of two cases. J Pediatr Adolesc Gynecol 1997; 10/4: 219-222

6 Dimopoulos MA, Daliani D, Pugh $W$ et al. Primary ovarian non-Hodgkin's lymphoma: outcome after treatment with combination chemotherapy. Gynecol Oncol 1997; 64: 446-450

7 Martín AJM, Fernández RP, Beneítez MCV et al. Primary ovarian Burkitt lymphoma. Clin Transl Oncol 2008; 10: 673-675

8 Guitiérrez-García L, Medina Ramos N, Rodríguez RG et al. Bilateral ovarian Burkitt's lymphoma. Eur J Gynaecol Oncol 2009; 30: 231-233

9 Hatami M, Whitney K, Goldberg GL. Primary bilateral ovarian and uterine Burkitt's lymphoma following chemotherapy for breast cancer. Arch Gynecol Obstet 2010; 281: 697-702
10 Vang $R$, Medeiros LJ, Warnke RA et al. Ovarian non-Hodgkin's lymphoma: a clinicopathologic study of eight primary cases. Mod Pathol 2001; 14: 1093-1099

11 Burkitt D. A sarcoma involving the jaws in African children. Br J Surg 1958; 46: 218-223

12 Wright DH, Addis BJ, Leong AS-Y. Diagnostic Lymph Node Pathology. 2nd ed. London: Hodder Arnold; 2011: 85-88

13 Blum KA, Lozanski G, Byrd JC. Adult Burkitt leukemia and lymphoma. Blood 2004; 104: 3009-3020

14 Yamada T, Iwao N, Kasamatzu H et al. A case of malignant lymphoma of the ovary manifesting like an advanced ovarian cancer. Gynecol Oncol 2003; 90: 215-219

Deutschsprachige Zusatzinformationen online abrufbar unter: www.thieme-connect.de/ejournals/toc/gebfra. 